\title{
Prevalence and correlates of painful conditions and multimorbidity in national sample of overweight/obese Veterans
}

\author{
Diana M. Higgins, PhD; ${ }^{*}$ Eugenia Buta, PhD; ${ }^{2-3}$ Lindsey Dorflinger, PhD; ${ }^{2,4}$ Robin M. Masheb, PhD; ${ }^{2,4}$ \\ Christopher B. Ruser, MD; ${ }^{2,4}$ Joseph L. Goulet, MS, PhD; ${ }^{2,4}$ Alicia A. Heapy, PhD $^{2,4}$ \\ ${ }^{1}$ Department of Veterans Affairs (VA) Boston Healthcare System, Boston, MA; and Department of Psychiatry, Boston \\ University School of Medicine, Boston, MA; ${ }^{2}$ VA Connecticut Healthcare System, West Haven, CT; ${ }^{3}$ Department of \\ Epidemiology, Yale School of Public Health, New Haven, CT; ${ }^{4}$ Yale School of Medicine, New Haven, CT
}

\begin{abstract}
Chronic pain and overweight/obesity are prevalent public health concerns and occur at particularly high rates among Veterans. This study examined the prevalence and correlates of two common painful conditions (back pain and arthritis/ joint pain) among overweight/obese Veterans in Veterans Health Administration (VHA) care. Participants $(N=45,477)$ completed the MOVE!23, a survey intended to tailor treatment for Veterans in VHA's MOVE! weight-management program. Overall, $72 \%$ of the sample reported painful conditions, with $10 \%$ reporting back pain, 26\% reporting arthritis/joint pain, and 35\% reporting both. We used multinomial logistic regression with "no pain" as the reference category to examine the association between painful conditions and participant characteristics. After multivariable adjustment, female Veterans had higher odds of reporting arthritis/joint pain and combined back and arthritis/ joint pain than no pain. Participants with higher body mass index had higher odds of reporting arthritis/joint pain and both back and arthritis/joint pain. The likelihood of painful conditions was higher in Veterans with comorbidities (hypertension, hyperlipidemia, lung disease, depression, anxiety, or posttraumatic stress disorder) and generally increased with the number of comorbidities reported (i.e., 5 or more). Overweight/obese Veterans frequently report painful conditions and, among those with pain, often have multiple comorbidities. These factors may increase the complexity of clinical management and necessitate refinements to weight-management programs.
\end{abstract}

Key words: arthritis, back pain, BMI, chronic pain, comorbidities, multimorbidity, obesity, overweight, Veterans, weight management.

\section{INTRODUCTION}

Pain and obesity are two of the most prevalent chronic diseases in the United States [1-3] and are especially common among Veterans treated within the Veterans Health Administration (VHA) [4-6]. Recent estimates of the prevalence of overweight/obesity are 68.0 percent for the general U.S. population [1] and 76.9 percent for Veterans within VHA [7]. Veterans also have higher waist circumferences than the general population [8]. While limited epidemiological data regarding pain is a recognized barrier to determining the prevalence of chronic pain in the United States [9], in the report, "Relieving pain in America: A blueprint for transforming prevention, care, education and research," the Institute of Medicine notes that approximately 100 million Americans experience chronic pain [9]. Recently, chronic pain in the general population, as

\footnotetext{
Abbreviations: $\mathrm{BMI}=$ body mass index, $\mathrm{CAD}=$ coronary artery disease, $\mathrm{CI}=$ confidence interval, $\mathrm{HTN}=$ hypertension, $\mathrm{OR}=$ odds ratio, $\mathrm{PTSD}=$ posttraumatic stress disorder, $\mathrm{VA}=$ Department of Veterans Affairs, VHA = Veterans Health Administration.

*Address all correspondence to Diana M. Higgins, PhD; VA Boston Healthcare System, 150 South Huntington Ave, 116B-2, Boston, MA 02130; 857-364-2221; fax: 857-3644501. Email: diana.higgins2@va.gov

http://dx.doi.org/10.1682/JRRD.2014.10.0251
} 
reported by national surveys, has been found to range from 19 [10] to 43 percent [11] among age, race/ethnicity, and/ or sex standardized national samples. The prevalence of chronic pain among Veterans appears to be comparable to or higher than non-Veterans, with one study showing a significantly higher rate of low back pain among Veterans compared with non-Veterans ( $44 \%$ vs $25 \%$, respectively) in primary care settings [2].

Similar to reported rates of overweight/obesity and chronic pain alone, rates of comorbid pain and overweight/ obesity are also high, with some estimates ranging from 20 to 45 percent of overweight/obese individuals reporting pain [12]. Recent data from the 2010 National Health Interview Survey demonstrated that among those with persistent pain (i.e., a duration of $\geq 3 \mathrm{mo}$ ) in the general U.S. population, 18.2 percent are overweight and 25.3 percent are obese [10]. Higher body mass index (BMI) was associated with increased risk of recent pain [13] and report of a painful condition within the previous year [12]. Further, obesity has been shown to predict the onset and progression of pain [14], and obese patients have reported engaging in poor eating habits and avoiding physical activity in response to pain [15].

The high rate of comorbidity between pain and overweight/obesity has implications for the treatment of both conditions. Patients commonly endorse pain as a barrier to weight loss [15-16], and obesity has been shown to moderate the impact of treatment for chronic pain selfmanagement in Veterans in VHA care [17]. There is some evidence supporting integrated interventions targeting both weight loss and improvement in physical functioning, though they tend to focus specifically on intensive interventions for patients with a narrowly defined type of painful condition, such as knee osteoarthritis [18-19].

More broadly, information regarding correlates of both pain and obesity is limited [20], particularly among Veterans receiving VHA care. There is a wealth of data describing high-prevalence, high-impact multimorbidity among Veterans in general [21-23]. There is also a wealth of data describing comorbidities among Veterans with overweight/obesity, such as hypertension (HTN), type 2 diabetes, hypercholesterolemia, and heart disease [7,24], as well as alcohol and drug use disorders, depression, and posttraumatic stress disorder (PTSD) [24]. The same is true for correlates of pain and painful conditions among Veterans, including overweight/obesity, anxiety disorders, PTSD, mood disorders, and substance use disorders [2526]. There is emerging evidence that pain interferes with the management of other chronic conditions, such as diabetes [27-28], and leads to poorer outcomes for both comorbid conditions, further suggesting a need to examine comorbid pain and obesity. Better management of both pain and overweight/obesity may lead to improved outcomes in both conditions.

Given the high prevalence of pain and overweight/ obesity among Veterans, as well as evidence suggesting that each may serve as a barrier to treatment of the other, further investigation is warranted to better understand the clinical correlates of Veterans with comorbid pain and overweight/obesity. The association between pain and overweight/obesity may have important implications for the potential refinement of weight-management programs, such as the VHA's national program, MOVE!. The objective of the current paper is to examine the prevalence and correlates of self-reported painful conditions, specifically arthritis/joint pain and back pain, among overweight/ obese Veterans expressing interest in weight-management treatment.

\section{METHODS}

\section{Participants}

The national sample consisted of 45,477 overweight/ obese Veterans who received healthcare in VHA facilities and expressed interest in weight management. Veterans in this sample had a self-reported weight and height consistent with a BMI $\geq 25$ and completed the MOVE! 23 survey in 2006. Survey data were collected during routine primary care screening from patients who expressed interest in the MOVE! weight-management program. However, not all patients who indicated interest and completed the MOVE!23 ultimately enrolled or participated in the MOVE! program.

\section{Data Source}

A secondary analysis of cross-sectional data collected using the MOVE!23 survey was conducted. The MOVE!23 was developed by VHA in conjunction with the VHA's National Center for Health Promotion and Disease Prevention as a clinical tool to assist providers in working with Veterans to achieve weight loss and improvement in related comorbid conditions. The survey contains 23 questions that assess demographics, weight history, medical and psychiatric comorbidities (including painful conditions), eating habits, exercise, and motivation and support 
[29]. The MOVE!23 survey was developed to aid in tailoring treatment for patients in the VHA's national MOVE! weight-management program.

While the measure as a whole does not have published psychometric properties, sections of the MOVE! 23 have been validated (e.g., perceived barriers and contributors to weight gain [25]).The MOVE!23 is inherently face valid, and the choice of items for inclusion in the current study included those questions that contained information about pain (i.e., painful conditions), selfreported demographics, and self-reported medical and mental health comorbidities to include in the analyses as covariates.

\section{Study Variables}

\section{Demographics}

Survey respondents reported their sex, age, and race/ ethnicity.

\section{Overweight/Obesity}

BMI was calculated using self-reported height (inches) and weight (pounds). BMI was categorized as: overweight (BMI 25.0 to $29.9 \mathrm{~kg} / \mathrm{m}^{2}$ ), class I obesity (BMI 30.0 to $34.9 \mathrm{~kg} / \mathrm{m}^{2}$ ), class II obesity (BMI 35.0 to $39.9 \mathrm{~kg} / \mathrm{m}^{2}$ ), and class III obesity (BMI $\left.\geq 40.0 \mathrm{~kg} / \mathrm{m}^{2}\right)$ [30].

\section{Comorbidities}

All medical and mental health comorbidities and related problems, as well as painful conditions, were derived from a single item on the MOVE!23 survey: "Please indicate any of the following that apply to you." There were 20 possible responses for medical comorbidities and acute and chronic medical conditions and problems and 13 possible responses for mental health comorbidities and related problems.

Medical comorbidities. Respondents reported past or current medical conditions, including diabetes, HTN, heart disease (coronary artery disease [CAD]), high blood cholesterol (hyperlipidemia), and lung disease (i.e., emphysema, chronic obstructive pulmonary disease, asthma). These 5 comorbidities, of the 20 possible responses, were targeted for examination for the current study because they are high-impact, high-prevalence chronic conditions among Veterans. These have also been highlighted in previous studies as comorbidities of overweight/obesity and/or painful conditions among Veterans [7,24]. We excluded assessed conditions that did not represent actual diagnoses (e.g., loss of balance because of dizziness or passing out, chest pains not previously evaluated by your doctor, shortness of breath at rest, amputation, someone in your immediate family with heart problems at an age $<50 \mathrm{yr}$, and poor circulation in the legs), those that were acute problems (e.g., active infection of any kind or any chronic medical problem that has recently been out-of-control, unstable, or flared up), those with low prevalence compared with other conditions among Veterans (e.g., hernia, retinal bleeding, spinal cord injury, osteoporosis, or bone disease), and those that were nonspecific (i.e., combined several conditions, symptoms, or procedures, such as stroke, transient ischemic attack, or carotid surgery in the neck).

Mental health comorbidities. Respondents reported past or current mental health conditions and other problems: depression, tobacco use/smoking, substance abuse or dependence, anxiety problems or nervousness, PTSD, bipolar disorder, schizophrenia, and obsessive compulsive disorder. These 8 mental health comorbidities, of the 12 possible responses, were targeted for examination for the current study because they are not only high-impact, high-prevalence mental health conditions among Veterans they are also comorbidities of overweight/obesity and/or painful conditions among Veterans [24-26]. The remaining conditions do not represent diagnoses and are too general to enhance the understanding of the population (e.g., general unhappiness, too much stress, and family or relationship problems) or are nonspecific (i.e., eating disorder).

\section{Pain Groups}

Participants were categorized into the following pain groups: no pain (i.e., neither back pain nor arthritis/joint pain), back pain only, arthritis/joint pain only, and combined back and arthritis/joint pain (i.e., those respondents who endorsed both pain problems) based on their endorsement of the "back pain or spinal disc disease" and "arthritis or joint pain" responses for the comorbidities item described previously.

\section{Analyses}

Descriptive statistics for demographic and clinical variables are presented by pain group and overall. Because the outcome pain group is a nominal categorical variable with 4 levels, we used a multinomial logistic regression model with the "no pain" (i.e., no "painful 
conditions") group as the reference category to simultaneously investigate the correlates of belonging to this group instead of the other three groups. Specifically, this model compares the probability of being in the "back pain only," "arthritis/joint pain only," or "both back and arthritis/joint pain" groups relative to the "no pain" group and relates these comparisons to the following subject demographic and clinical characteristics: sex, age (categorical variable with categories 21-34, 35-44, 45-54, 55-64, 65-74, and $\geq 75 \mathrm{yr}$ ), race/ethnicity (White, Black/ African American, Hispanic, or Other), BMI class (overweight and obese class I, II, or III), and the medical and mental comorbidities described previously (each categorized as present/absent). We present the adjusted odds ratios (ORs) from the multinomial logistic regression model as a measure of association between pain group and subject characteristics. To investigate the association between number of comorbidities and pain group, we fit an additional multinomial logit model including as predictors number of comorbidities (categorical variable with values $0,1,2,3,4$, and $\geq 5$ ), age, sex, race/ethnicity, and BMI class.

We performed multiple imputation to avoid potentially biasing the results by excluding subjects with missing race/ethnicity (16\%) from the analysis. This method assumes that the data are "missing at random"; i.e., that the probability of missingness depends only on observed data. We generated 10 complete data sets via predictive mean matching imputation (as implemented by the "aregImpute" function within the "Hmisc" package in the statistical software R [R Foundation; Vienna, Austria]), separately analyzed each data set by fitting a multinomial logistic regression model, and then combined results across data sets by using Rubin's rules. The imputed results are reported in this article. Because our sample was large and statistically significant differences may not reflect clinically significant findings, we focus on results that were high in magnitude in terms of ORs (i.e., significantly greater or less than 1.0) and also statistically significant at the 0.05 level.

\section{RESULTS}

Of the 45,477 subjects in our sample, 28 percent of participants reported "no pain" (i.e., no back or arthritis/ joint pain), 10 percent reported "back pain" only, 26 percent reported "arthritis/joint pain" only, and 35 percent reported "both back and arthritis/joint pain." Table 1 contains the characteristics of the sample by pain group and overall. Subjects were mostly male $(86.6 \%)$ and had a mean \pm standard deviation (SD) age of $57.3 \pm 11.4$. Subjects in the "back pain only" group were slightly younger than the rest, and those in the three painful conditions groups were more likely to be in higher BMI categories than those in the "no pain" group. Overall, the most commonly reported medical comorbidities were HTN (62.5\%), hyperlipidemia (47.7\%), and diabetes (36.5\%), which were all less likely to be reported by the "no pain" group than the other three groups. Depression $(36.4 \%)$, anxiety $(30.0 \%)$, and PTSD $(21.1 \%)$ were the most prevalent mental health comorbidities and were less common in the "no pain" group than in the other groups. The mean number of comorbidities in the overall sample was $3.0 \pm 2.0$ and was lower on average in the "no pain" group than in the other groups. Veterans in the "both back and arthritis/joint pain" group were most likely to report $\geq 5$ comorbidities, with 32.3 percent of the back and arthritis/joint pain group reporting $\geq 5$ comorbidities.

Table 2 contains the results obtained from multinomial logistic regression after imputing the missing race/ ethnicity data. For each predictor, the table gives estimates of the adjusted ORs of being in each of the three pain groups (the back pain only, arthritis/joint pain only, or both) instead of the reference no pain group and associated 95 percent confidence intervals (CIs).

After controlling for the other predictors in the model, male Veterans had lower odds of reporting "arthritis/joint pain only" (OR $=0.76 ; 95 \%$ CI 0.70 to 0.83$)$ and "both back and arthritis/joint pain" (OR $=0.75 ; 95 \%$ CI 0.69 to 0.81) than "no pain" compared with female Veterans. Older Veterans ( $\geq 35 \mathrm{yr}$ ) were more likely than younger ones (reference 21-34 yr) to report "arthritis/joint pain only" and "both back and arthritis/joint pain" than "no pain" and less likely to report "back pain only" than "no pain." The estimated odds of being in the "arthritis/joint pain only" and "both back and arthritis/joint pain" groups versus the "no pain" group increased with increasing BMI class.

Participants who endorsed HTN, CAD, or lung disease had higher odds than participants without those conditions of being in the three painful conditions groups instead of the "no pain" group (all corresponding OR significantly $>1$ ). Similarly, participants with depression, anxiety, or PTSD were more likely than those without those conditions to be in any of the three painful conditions groups (OR significantly $>1$ ). Those who reported 
Table 1.

Descriptive statistics by pain group and overall (percent/frequency).

\begin{tabular}{|c|c|c|c|c|c|}
\hline Variable & $\begin{array}{c}\text { No Pain } \\
N=12,812(28 \%)\end{array}$ & $\begin{array}{l}\text { Back Pain Only } \\
N=4,766(10 \%)\end{array}$ & $\begin{array}{c}\text { Arthritis/Joint } \\
\text { Pain Only } \\
N=\mathbf{1 1 , 7 9 0 ( 2 6 \% )}\end{array}$ & $\begin{array}{c}\text { Both Back \& } \\
\text { Arthritis/Joint Pain } \\
N=16,109(35 \%)\end{array}$ & $\begin{array}{c}\text { Overall } \\
N=\mathbf{4 5 , 4 7 7}(100 \%)\end{array}$ \\
\hline Male & $87.8(11,243)$ & $85.1(4,058)$ & $87.7(10,337)$ & $85.3(13,746)$ & $86.6(39,384)$ \\
\hline \multicolumn{6}{|l|}{ Age Category } \\
\hline $21-34$ & $5.0(637)$ & $7.5(358)$ & $2.5(300)$ & $2.8(446)$ & $3.8(1,741)$ \\
\hline $55-64$ & $38.9(4,983)$ & $38.3(1,825)$ & $43.6(5,136)$ & $44.5(7,170)$ & $42.0(19,114)$ \\
\hline $65-74$ & $19.2(2,464)$ & $12.6(599)$ & $21.2(2,494)$ & $15.3(2,462)$ & $17.6(8,019)$ \\
\hline$\geq 75$ & $6.6(850)$ & $4.0(192)$ & $8.0(946)$ & $4.9(795)$ & $6.1(2,783)$ \\
\hline \multicolumn{6}{|l|}{ Ethnicity/Race } \\
\hline White & $57.0(7,308)$ & $54.9(2,617)$ & $59.6(7,032)$ & $60.1(9,678)$ & $58.6(26,635)$ \\
\hline Declined to Report & $17.1(2,196)$ & $15.9(756)$ & $15.5(1,825)$ & $15.8(2,545)$ & $16.1(7,322)$ \\
\hline BMI, median (IQR) & $34.6(31.4-39.1)$ & $35.4(31.8-39.9)$ & $36.0(32.2-40.9)$ & $36.5(32.6-41.7)$ & $35.7(32.1-40.6)$ \\
\hline \multicolumn{6}{|l|}{ BMI Class } \\
\hline Overweight & $14.9(1,906)$ & $13.6(648)$ & $11.3(1,332)$ & $10.1(1,620)$ & $12.1(5,506)$ \\
\hline Obese Class I & $38.2(4,900)$ & $33.6(1,599)$ & $32.6(3,842)$ & $30.6(4,930)$ & $33.6(15,271)$ \\
\hline Obese Class II & $25.3(3,242)$ & $28.4(1,352)$ & $27.6(3,249)$ & $27.4(4,408)$ & $26.9(12,251)$ \\
\hline Obese Class III & $21.6(2,764)$ & $24.5(1,167)$ & $28.6(3,367)$ & $32.0(5,151)$ & $27.4(12,449)$ \\
\hline \multicolumn{6}{|l|}{ Comorbidities } \\
\hline HTN & $55.1(7,054)$ & $58.4(2,781)$ & $65.5(7,728)$ & $67.3(10,838)$ & $62.5(28,401)$ \\
\hline Diabetes & $32.6(4,178)$ & $33.8(1,610)$ & $39.2(4,621)$ & $38.5(6,210)$ & $36.5(16,619)$ \\
\hline Anxiety & $18.7(2,401)$ & $31.8(1,515)$ & $26.0(3,071)$ & $41.2(6,639)$ & $30.0(13,626)$ \\
\hline PTSD & $13.3(1,702)$ & $22.5(1,073)$ & $18.2(2,143)$ & $29.2(4,698)$ & $21.1(9,616)$ \\
\hline Bipolar Disorder & $4.5(582)$ & 6.7 (318) & $4.3(512)$ & $7.8(1,249)$ & $5.9(2,661)$ \\
\hline Schizophrenia & $3.3(420)$ & $2.6(125)$ & $2.0(240)$ & $2.7(429)$ & $2.7(1,214)$ \\
\hline OCD & $3.3(420)$ & $5.2(246)$ & $4.4(520)$ & $7.7(1,242)$ & $5.3(2,428)$ \\
\hline \multicolumn{6}{|l|}{ No. Comorbidities } \\
\hline 0 & $12.7(1,629)$ & $9.0(429)$ & $8.1(957)$ & $4.7(760)$ & $8.3(3,775)$ \\
\hline 1 & $21.7(2,774)$ & $15.5(740)$ & $15.7(1,850)$ & $10.6(1,713)$ & $15.6(7,077)$ \\
\hline 2 & $22.8(2,925)$ & $19.1(912)$ & $20.7(2,437)$ & $15.6(2,506)$ & $19.3(8,780)$ \\
\hline 3 & $19.7(2,526)$ & $18.9(899)$ & $20.4(2,406)$ & $18.9(3,052)$ & $19.5(8,883)$ \\
\hline 4 & $11.7(1,498)$ & $15.4(736)$ & $15.8(1,860)$ & $17.8(2,874)$ & $15.3(6,968)$ \\
\hline$\geq 5$ & $11.4(1,460)$ & $22.0(1,050)$ & $19.3(2,280)$ & $32.3(5,204)$ & $22.0(9,994)$ \\
\hline Mean \pm SD & $2.4 \pm 1.7$ & $3.0 \pm 2.0$ & $2.9 \pm 1.9$ & $3.7 \pm 2.1$ & $3.0 \pm 2.0$ \\
\hline
\end{tabular}


JRRD, Volume 53, Number 1, 2016

Table 2.

Adjusted odds ratio (OR) estimates from multivariable multinomial logistic model fit on $N=45,477$ subjects (imputed results).

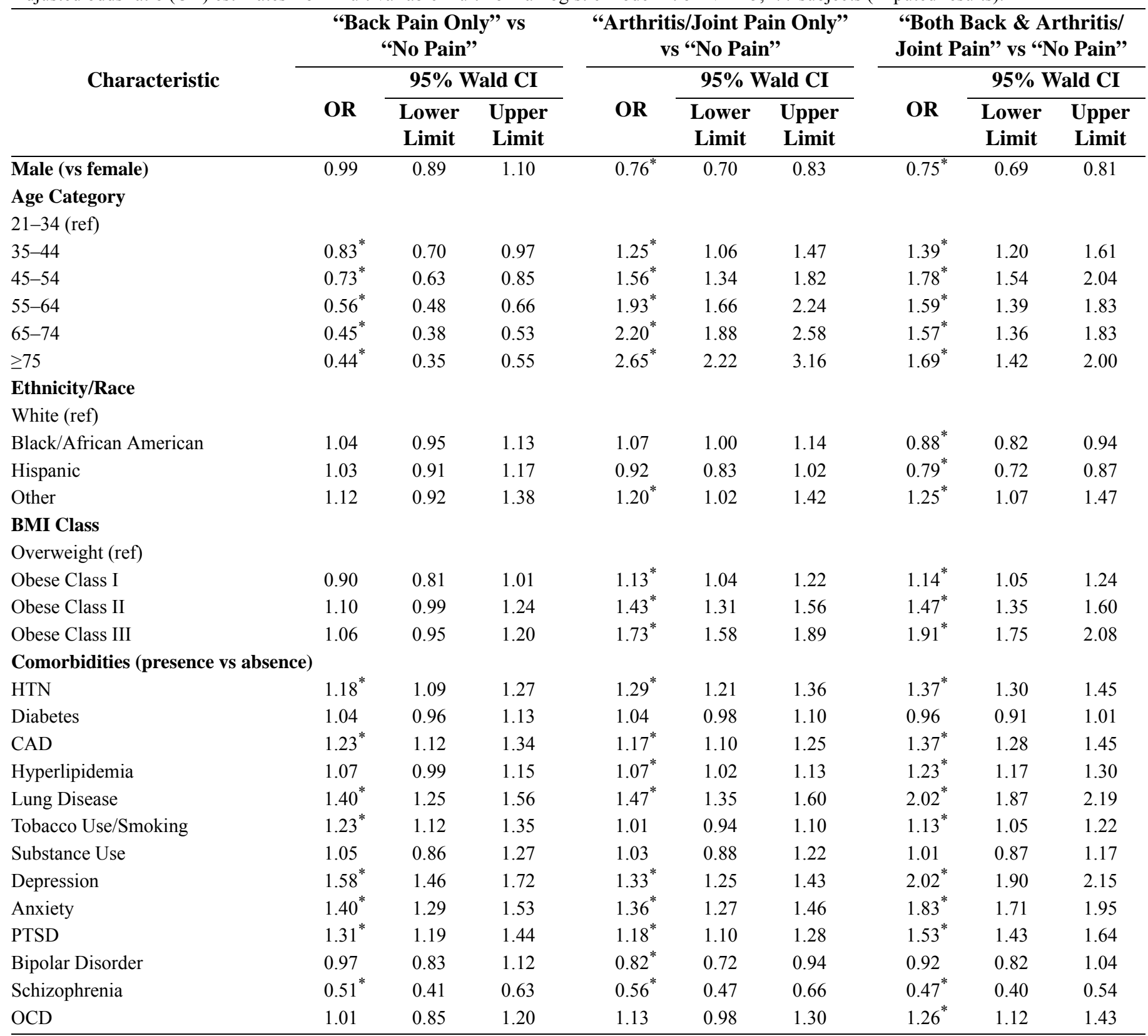

Note: Model used pain group (with categories "back pain only," "arthritis/joint pain only," and "both back and arthritis/joint pain" vs reference category "no pain") as an outcome and simultaneously adjusted for all predictors listed in table. ${ }^{*} p \leq 0.05$.

$\mathrm{BMI}=$ body mass index, $\mathrm{CAD}=$ coronary artery disease, $\mathrm{CI}=$ confidence interval, $\mathrm{HTN}=$ hypertension, $\mathrm{OCD}=$ obsessive compulsive disorder, $\mathrm{PTSD}=$ posttraumatic stress disorder, ref $=$ reference.

schizophrenia had markedly higher odds than those without schizophrenia to report being in the reference "no pain" group relative to the other three groups.

Table 3 presents adjusted OR estimates for the association between number of comorbidities and pain group.
A higher number of comorbidities was generally associated with higher odds of being in the three groups with pain rather than in the "no pain" group. Notably, those reporting $\geq 5$ comorbidities were substantially more likely to be in the "back pain only" group (adjusted OR 3.00, 
Table 3.

Adjusted odds ratio (OR) estimates for number of comorbidities from multivariable multinomial logistic model fit on $N=45,477$ subjects (imputed results).

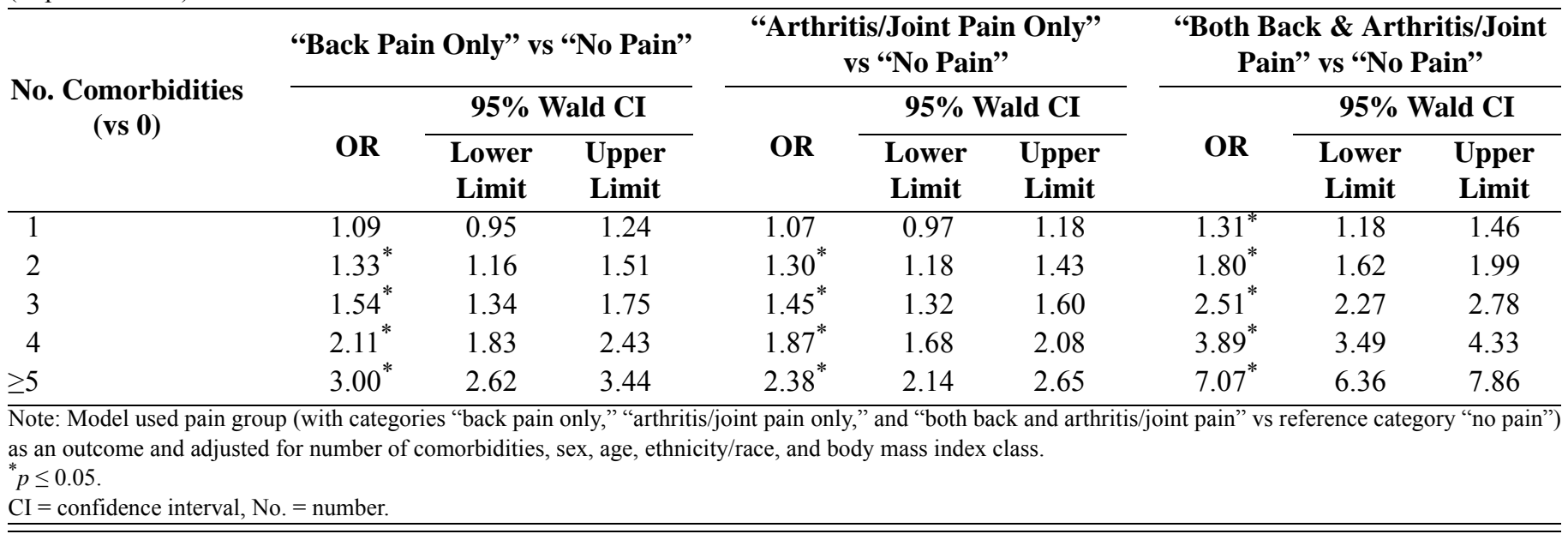

95\% CI 2.62 to 3.44), "arthritis/joint pain only" group (adjusted OR 2.38, 95\% CI 2.14 to 2.65), or "both back and arthritis/joint pain" group (adjusted OR 7.07, 95\% CI 6.36 to 7.86 ) than in the "no pain" group.

\section{DISCUSSION}

A very high proportion of the sample (72\%) of overweight/obese Veterans reported $\geq 1$ painful condition, with 10 percent reporting back pain only, 26 percent reporting arthritis/joint pain only, and 35 percent reporting combined back and arthritis/joint pain. Participants with higher BMIs were more likely to report painful conditions (i.e., arthritis/ joint pain or both back and arthritis/joint pain). Among Veterans with combined back and arthritis/joint pain, the proportion with any given comorbid condition was quite high (e.g., 67.3\% HTN, 38.5\% diabetes, 52.8\% hyperlipidemia, 20.2\% lung disease, $49.5 \%$ depression, and $41.2 \%$ anxiety), and those patients were most likely to report $\geq 5$ comorbidities $(32.3 \%)$. Given the emerging evidence that pain interferes with the self-management of other conditions or is associated with poorer outcomes (e.g., diabetes, PTSD), it may be helpful to examine the role of pain in weight-management outcomes and potentially address pain in weight-management programs such as MOVE! [28].

The literature on comorbid pain and overweight/obesity shows that patients frequently endorse pain as a barrier to weight loss [15-16]. Given that this study examined a large sample of Veterans with overweight/obesity who were inter- ested in weight management, the finding that the vast majority are experiencing painful conditions is likely to have an effect on the success of traditional weight-management programs, such as the VHA's MOVE! program, which encourage physical activity. Weight loss programs such as MOVE! may need to be modified to address pain management through the addition of pain education and behavioral pain self-management skills. For example, if patients are able to learn appropriate pain self-management skills, such as task persistence, pacing, and cognitive restructuring, pain may serve as less of a barrier to increasing physical activity, thus theoretically improving weight loss outcomes.

One compelling feature of the data presented in the current study is that Veterans who are interested in MOVE! have an extremely high burden of comorbidity, particularly those with $>1$ painful condition (i.e., the Veterans reporting $\geq 5$ comorbidities were most likely to report 2 painful conditions). This is a possible explanation for the low mean weight loss seen in the MOVE! program [31]. Although MOVE! was designed on a population health approach and was developed to be a low barrier to entry program that would attract as many Veterans as possible, the patients who attend have multimorbidities, including extremely high rates of painful conditions, that likely complicate care and interfere with their weight loss efforts. Efforts to adapt MOVE! for Veterans with complex psychiatric illnesses may provide a model for how to do this for Veterans with comorbid pain conditions [32].

Generally, patients with medical and mental health conditions were more likely than those without the conditions to report being in each of the three groups with pain 
(the back pain only, arthritis/joint pain only, and both back and arthritis/joint pain groups) rather than in the group without pain. In particular, they had the highest adjusted odds of being in the combined back and arthritis/joint pain group. This is consistent with recent Veteran data demonstrating that those with persistent pain were more likely to report comorbid conditions, including diagnoses of mood disorders, PTSD, substance use disorders, anxiety disorders, and traumatic brain injury; they were also more likely to have a BMI consistent with overweight/obesity [33]. Other research has shown that those with multiple painful conditions have a number of additional medical and mental health comorbidities, along with higher burden of illness and cost of care [34]. Properly addressing chronic pain in medically complex patients may improve health status, functioning, and quality of life, in addition to improving other health conditions [28].

A previous study of Operation Iraqi Freedom/Operation Enduring Freedom Veterans showed sex differences in the prevalence and severity of pain [26]. Similarly, female Veterans in the current study were more likely to report arthritis/joint pain and combined back and arthritis/joint pain than male Veterans. Despite controlling for variables such as age, race, and BMI, all of which are typically associated with differences in reporting of pain and painful conditions, this difference between male and female Veterans persisted. Female Veterans with overweight/obesity may be especially vulnerable to less-thandesirable weight loss outcomes if pain is not addressed in the context of weight-management programs.

In the current study, patients with comorbid mental health conditions, including depression and PTSD, were more likely than those without the conditions to report being in the groups with pain (the back pain only, arthritis/joint pain only, and both back and arthritis/joint pain groups) relative to the "no pain" group, a finding that is consistent with existing data describing Veterans with chronic pain [33,35-38]. However, those patients reporting comorbid schizophrenia were less likely to report back pain or arthritis/joint pain. The limited literature on persistent pain in patients with schizophrenia is mixed. The results in the current study are consistent with an administrative data study of VHA patients with schizophrenia that found lower associations between schizophrenia and pain conditions than for those without a serious mental illness after controlling for demographic variables [39]. In contrast, another recent study found the prevalence and intensity of pain appears to be compara- ble between those with schizophrenia and those without, with the exception of more acute, severe pain such as headache following lumbar puncture, in which patients with schizophrenia are less likely to report pain [40].

Importantly, the current study included a large sample of nearly 46,000 patients. Given the sample size, it is not surprising that many of the associations were statistically significant. Because clinical meaningfulness is difficult to assess based on the OR, it may be helpful to consider covariate-adjusted absolute proportions ("recycled predictions"; Table 4) [41]. When considering the effect of BMI category, for example, these proportions allow us to compare the estimated distribution of the outcome across BMI categories while keeping constant all other covariates at the observed values. After adjusting for the other covariates, 31 percent of overweight patients reported "both back and arthritis/joint pain," whereas 40 percent of patients with class III obesity reported "both back and arthritis/joint pain." This is an absolute difference in proportions of 9 percent, which translates into a large number of patients reporting severe obesity and comorbid back and arthritis/ joint pain.

The current study has several limitations. One significant limitation is that the MOVE!23 was the sole source of data; thus all data are self-reported (i.e., height, weight, and comorbidities) and obtained from a small proportion of Veterans who were interested in weight management among the estimated 73 percent of Veterans in VHA care with overweight/obesity [4]. More specifically, the MOVE!23 question from which data for painful conditions and comorbidities for the current study were derived does not specifically ask about "diagnosed" conditions. It simply asks patients to determine whether each condition applies to them. This limits the validity of the diagnoses reported in the results of the current study. In addition, given that our sample has a higher average BMI than is found in the population of Veterans in VHA care, it is not surprising that the high prevalence of comorbidity and pain reporting is greater than typically seen in the general Veteran population.

Because these data were limited to endorsement or nonendorsement of a painful condition, the magnitude of pain and pain-related functional interference was not assessed. This limits the generalizations about pain in this sample because there is no multidimensional assessment of pain variables, including the chronicity of pain. Further, the survey included questions about only common musculoskeletal pain conditions and did not assess other common painful conditions. Thus, it must be 
Table 4.

Covariate-adjusted proportions in each pain group by subject characteristics ("recycled predictions" obtained from multinomial logit model in Table 2).

\begin{tabular}{ccccc}
\hline Variable & $\begin{array}{c}\text { No } \\
\text { Pain }\end{array}$ & $\begin{array}{c}\text { Back } \\
\text { Pain }\end{array}$ & $\begin{array}{c}\text { Arthritis/ } \\
\text { Joint Pain }\end{array}$ & $\begin{array}{c}\text { Both Back } \\
\text { \& Arthritis/ } \\
\text { Joint Pain }\end{array}$ \\
\hline
\end{tabular}

Sex
Female
Male
Age Category
$21-34$
$35-44$
$45-54$
$55-64$
$65-74$
$\geq 75$
Ethnicity/Race
White
Black/African American
Hispanic
Other
BMI Class

Overweight

Obese Class I

Obese Class II

Obese Class III

Comorbidities

No HTN

HTN

No Diabetes

Diabetes

No CAD

$\mathrm{CAD}$

No Hyperlipidemia

Hyperlipidemia

No Lung Disease

Lung Disease

No Tobacco Use/Smoking

Tobacco Use/Smoking

No Substance Use

Substance Use

No Depression

Depression

No Anxiety

Anxiety

No PTSD

PTSD

No Bipolar Disorder

Bipolar Disorder

No Schizophrenia

Schizophrenia

No OCD

24
28
34
31
27
28
27
25

.

$\begin{array}{rrr}9 & 28 & 39 \\ 11 & 26 & 35\end{array}$

39
35

5

$\begin{array}{rrr}21 & 18 & 28 \\ 16 & 19 & 34 \\ 12 & 22 & 38 \\ 9 & 27 & 36 \\ 7 & 31 & 34 \\ 7 & 33 & 35\end{array}$

$\begin{array}{llll}28 & 10 & 26 & 36\end{array}$

28

30

23

11

$$
28
$$$$
33
$$$$
32
$$$$
40
$$

33

31

23

31

26

28

28

29

25

29

26

29

20

28

26

28

27

31

22

30

22

29

23

28

31

27

42

28

OCD

$25 \quad 10$

BMI $=$ body mass index, $\mathrm{CAD}=$ coronary artery disease, $\mathrm{HTN}=$ hypertension, $\mathrm{OCD}=$ obsessive compulsive disorder, $\mathrm{PTSD}=$ posttraumatic stress disorder. assumed that some participants in the no pain group had other common pain conditions, such as neuropathy or headache. An interesting question is whether musculoskeletal conditions are particularly relevant in the context of management of weight problems. Future research could consider a broader array of painful conditions and examine questions about specificity of associations between pain and overweight/obesity. Finally, this study was crosssectional and the directional nature of relationships examined in this study cannot be determined.

Identifying subgroups of the overweight/obese population (such as those with painful conditions) allows for future research to determine whether these groups can be adequately treated with existing services or whether modifications are needed to address chronic pain and prevalent pain-related comorbidities within the VHA's national weight-management program, MOVE!. Examining the association between painful conditions and overweight/ obesity may assist with determining whether painful conditions add to the complexity of clinical management and may have implications for the potential need to refine weight-management treatment to address pain.

\section{CONCLUSIONS}

A majority of Veterans with overweight/obesity in our sample also reported $\geq 1$ painful condition. These patients also reported a very high burden of comorbidity, particularly those with $\geq 1$ painful condition (i.e., the Veterans reporting $\geq 5$ comorbidities were most likely to report 2 painful conditions). This multimorbidity may have a significant effect on the outcomes of existing weightmanagement programs, such as MOVE!, which may need to be modified to address pain management for optimal response among Veterans with these high-prevalence health concerns.

\section{ACKNOWLEDGMENTS}

\section{Author Contributions:}

Study concept and design: D. M. Higgins, R. M. Masheb.

Statistical analysis: E. Buta.

Analysis and interpretation of data: D. M. Higgins, E. Buta, J. L. Goulet. Drafting of manuscript: D. M. Higgins, E. Buta, L. Dorflinger. Critical revision of manuscript for important intellectual content: D. M. Higgins, L. Dorflinger, R. M. Masheb, C. B. Ruser, A. A. Heapy. Study supervision: J. L. Goulet, A. A. Heapy. 
Financial Disclosures: The authors have declared that no competing interests exist.

Funding/Support: This material was based on work that was unfunded at the time of manuscript preparation.

Additional Contributions: Data were compiled, managed, and provided by Tony Rogers, program analyst, and Susan Raffa, PhD, National Program Director for Weight Management/MOVE! at the VA National Center for Health Promotion and Disease Prevention. We would like to thank Robert $\mathrm{D}$. Kerns, $\mathrm{PhD}$, for providing feedback on a draft of the manuscript.

Institutional Review: This study was approved by the Institutional Review Boards of the VA Connecticut Healthcare System and Yale School of Medicine.

Participant Follow-Up: The authors have no plans to notify the study subjects of the publication of this article because of a lack of contact information.

Disclaimer: The views expressed in this article are those of the authors and do not necessarily represent the position or policy of the VA.

\section{REFERENCES}

1. Flegal KM, Carroll MD, Ogden CL, Curtin LR. Prevalence and trends in obesity among US adults, 1999-2008. JAMA. 2010;303(3):235-41. [PMID:20071471] http://dx.doi.org/10.1001/jama.2009.2014

2. Reid MC, Engles-Horton LL, Weber MB, Kerns RD, Rogers EL, O'Connor PG. Use of opioid medications for chronic noncancer pain syndromes in primary care. J Gen Intern Med. 2002;17(3):173-79. [PMID:11929502] http://dx.doi.org/10.1046/j.1525-1497.2002.10435.x

3. Upshur CC, Luckmann RS, Savageau JA. Primary care provider concerns about management of chronic pain in community clinic populations. J Gen Intern Med. 2006; 21(6):652-55. [PMID:16808752] http://dx.doi.org/10.1111/j.1525-1497.2006.00412.x

4. Das SR, Kinsinger LS, Yancy WS Jr, Wang A, Ciesco E, Burdick M, Yevich SJ. Obesity prevalence among Veterans at Veterans Affairs medical facilities. Am J Prev Med. 2005;28(3):291-94. [PMID:15766618] http://dx.doi.org/10.1016/j.amepre.2004.12.007

5. Gironda RJ, Clark ME, Massengale JP, Walker RL. Pain among Veterans of Operations Enduring Freedom and Iraqi Freedom. Pain Med. 2006;7(4):339-43. [PMID:16898945] http://dx.doi.org/10.1111/j.1526-4637.2006.00146.x

6. Kerns RD, Otis J, Rosenberg R, Reid MC. Veterans' reports of pain and associations with ratings of health, health-risk behaviors, affective distress, and use of the healthcare system. J Rehabil Res Dev. 2003;40(5):371-79. [PMID:15080222] http://dx.doi.org/10.1682/JRRD.2003.09.0371

7. Kahwati LC, Lance TX, Jones KR, Kinsinger LS. RE-AIM evaluation of the Veterans Health Administration's MOVE! weight management program. Transl Behav Med.
2011;1(4):551-60. [PMID:24073079]

http://dx.doi.org/10.1007/s13142-011-0077-4

8. Koepsell TD, Littman AJ, Forsberg CW. Obesity, overweight, and their life course trajectories in Veterans and non-Veterans. Obesity (Silver Spring). 2012;20(2):434-39. [PMID:21293452]

http://dx.doi.org/10.1038/oby.2011.2

9. Institute of Medicine. Relieving pain in America: A blueprint for transforming prevention, care, education and research. Washington (DC): The National Academies Press; 2011.

10. Kennedy J, Roll JM, Schraudner T, Murphy S, McPherson S. Prevalence of persistent pain in the U.S. adult population: New data from the 2010 national health interview survey. J Pain. 2014;15(10):979-84. [PMID:25267013] http://dx.doi.org/10.1016/j.jpain.2014.05.009

11. Tsang A, Von Korff M, Lee S, Alonso J, Karam E, Angermeyer MC, Borges GL, Bromet EJ, Demytteneare K, de Girolamo G, de Graaf R, Gureje O, Lepine JP, Haro JM, Levinson D, Oakley Browne MA, Posada-Villa J, Seedat S, Watanabe M. Common chronic pain conditions in developed and developing countries: Gender and age differences and comorbidity with depression-anxiety disorders. J Pain. 2008;9(10):883-91. Erratum in J Pain. 2009 May;10(5): 553. [PMID:18602869] http://dx.doi.org/10.1016/j.jpain.2008.05.005

12. Stone AA, Broderick JE. Obesity and pain are associated in the United States. Obesity (Silver Spring). 2012;20(7): 1491-95. [PMID:22262163] http://dx.doi.org/10.1038/oby.2011.397

13. Wright LJ, Schur E, Noonan C, Ahumada S, Buchwald D, Afari N. Chronic pain, overweight, and obesity: Findings from a community-based twin registry. J Pain. 2010;11(7): 628-35. [PMID:20338816] http://dx.doi.org/10.1016/j.jpain.2009.10.004

14. Jinks C, Jordan KP, Blagojevic M, Croft P. Predictors of onset and progression of knee pain in adults living in the community. A prospective study. Rheumatology (Oxford). 2008;47(3):368-74. [PMID:18263594] http://dx.doi.org/10.1093/rheumatology/kem374

15. Amy Janke E, Kozak AT. "The more pain I have, the more I want to eat": Obesity in the context of chronic pain. Obesity (Silver Spring). 2012;20(10):2027-34.

[PMID:22334258] http://dx.doi.org/10.1038/oby.2012.39

16. Howarth D, Inman D, Lingard E, McCaskie A, Gerrand C. Barriers to weight loss in obese patients with knee osteoarthritis. Ann R Coll Surg Engl. 2010;92(4):338-40. [PMID:20385042] http://dx.doi.org/10.1308/003588410X12628812458653

17. Sellinger JJ, Clark EA, Shulman M, Rosenberger PH, Heapy AA, Kerns RD. The moderating effect of obesity on 
cognitive-behavioral pain treatment outcomes. Pain Med. 2010;11(9):1381-90. [PMID:20735748]

http://dx.doi.org/10.1111/j.1526-4637.2010.00935.x

18. Messier SP, Loeser RF, Miller GD, Morgan TM, Rejeski WJ, Sevick MA, Ettinger WH Jr, Pahor M, Williamson JD. Exercise and dietary weight loss in overweight and obese older adults with knee osteoarthritis: The Arthritis, Diet, and Activity Promotion Trial. Arthritis Rheum. 2004; 50(5):1501-1510. [PMID:15146420]

http://dx.doi.org/10.1002/art.20256

19. Messier SP, Mihalko SL, Legault C, Miller GD, Nicklas BJ, DeVita P, Beavers DP, Hunter DJ, Lyles MF, Eckstein F, Williamson JD, Carr JJ, Guermazi A, Loeser RF. Effects of intensive diet and exercise on knee joint loads, inflammation, and clinical outcomes among overweight and obese adults with knee osteoarthritis: The IDEA randomized clinical trial. JAMA. 2013;310(12):1263-73. [PMID:24065013] http://dx.doi.org/10.1001/jama.2013.277669

20. Janke EA, Collins A, Kozak AT. Overview of the relationship between pain and obesity: What do we know? Where do we go next? J Rehabil Res Dev. 2007;44(2):245-62. [PMID:17551876] http://dx.doi.org/10.1682/JRRD.2006.06.0060

21. Goulet JL, Fultz SL, Rimland D, Butt A, Gibert C, Rodriguez-Barradas M, Bryant K, Justice AC. Aging and infectious diseases: Do patterns of comorbidity vary by HIV status, age, and HIV severity? Clin Infect Dis. 2007;45(12): 1593-601. [PMID:18190322]

http://dx.doi.org/10.1086/523577

22. Yoon J, Zulman D, Scott JY, Maciejewski ML. Costs associated with multimorbidity among VA patients. Med Care. 2014;52(Suppl 3):S31-36. [PMID:24561756] http://dx.doi.org/10.1097/MLR.0000000000000061

23. Babson KA, Del Re AC, Bonn-Miller MO, Woodward SH. The comorbidity of sleep apnea and mood, anxiety, and substance use disorders among obese military Veterans within the Veterans Health Administration. J Clin Sleep Med. 2013;9(12):1253-58. [PMID:24340286]

24. Noël PH, Copeland LA, Pugh MJ, Kahwati L, Tsevat J, Nelson K, Wang CP, Bollinger MJ, Hazuda HP. Obesity diagnosis and care practices in the Veterans Health Administration. J Gen Intern Med. 2010;25(6):510-16.

[PMID:20180155]

http://dx.doi.org/10.1007/s11606-010-1279-z

25. Higgins DM, Buta E, Dorflinger L, Heapy AA, Ruser CB, Goulet JL, Masheb RM. Psychometric properties of a MOVE!23 subscale: Perceived Contributors to Weight Change in a national sample of Veterans. J Health Psychol. 2014. Epub ahead of print. [PMID:25293969] http://dx.doi.org/10.1177/1359105314554530

26. Haskell SG, Brandt CA, Krebs EE, Skanderson M, Kerns RD, Goulet JL. Pain among Veterans of Operations Endur- ing Freedom and Iraqi Freedom: Do women and men differ? Pain Med. 2009;10(7):1167-73. [PMID:19818028] http://dx.doi.org/10.1111/j.1526-4637.2009.00714.x

27. Krein SL, Heisler M, Piette JD, Makki F, Kerr EA. The effect of chronic pain on diabetes patients' self-management. Diabetes Care. 2005;28(1):65-70. [PMID:15616235] http://dx.doi.org/10.2337/diacare.28.1.65

28. Butchart A, Kerr EA, Heisler M, Piette JD, Krein SL. Experience and management of chronic pain among patients with other complex chronic conditions. Clin J Pain. 2009;25(4): 293-98. [PMID:19590477] http://dx.doi.org/10.1097/AJP.0b013e31818bf574

29. Kinsinger LS, Jones KR, Kahwati L, Harvey R, Burdick M, Zele V, Yevich SJ. Design and dissemination of the MOVE! Weight-Management Program for Veterans. Prev Chronic Dis. 2009;6(3):A98. [PMID:19527600]

30. National Heart, Lung, and Blood Institute. Clinical guidelines on the identification, evaluation, and treatment of overweight and obesity in adults: Evidence report [Internet]. Bethesda (MD): National Heart, Lung, and Blood Institute; 1998 [cited 2014 July 16] Available from: http://www.ncbi.nlm.nih.gov/books/NBK2003/

31. Dahn JR, Fitzpatrick SL, Llabre MM, Apterbach GS, Helms RL, Cugnetto ML, Klaus J, Florez H, Lawler T. Weight management for Veterans: Examining change in weight before and after MOVE!. Obesity (Silver Spring). 2011;19(5):977-81. [PMID:21127474] http://dx.doi.org/10.1038/oby.2010.273

32. Goldberg RW, Reeves G, Tapscott S, Medoff D, Dickerson F, Goldberg AP, Ryan AS, Fang LJ, Dixon LB. "MOVE!" Outcomes of a weight loss program modified for Veterans with serious mental illness. Psychiatr Serv. 2013;64(8): 737-44. [PMID:23584716] http://dx.doi.org/10.1176/appi.ps.201200314

33. Higgins DM, Kerns RD, Brandt CA, Haskell SG, Bathulapalli H, Gilliam W, Goulet JL. Persistent pain and comorbidity among Operation Enduring Freedom/Operation Iraqi Freedom/Operation New Dawn Veterans. Pain Med. 2014; 15(5):782-90. [PMID:24548466] http://dx.doi.org/10.1111/pme.12388

34. Davis JA, Robinson RL, Le TK, Xie J. Incidence and impact of pain conditions and comorbid illnesses. J Pain Res. 2011;4:331-45. [PMID:22090802] http://dx.doi.org/10.2147/JPR.S24170

35. Otis JD, Keane TM, Kerns RD. An examination of the relationship between chronic pain and post-traumatic stress disorder. J Rehabil Res Dev. 2003;40(5):397-405.

[PMID:15080224] http://dx.doi.org/10.1682/JRRD.2003.09.0397

36. Otis JD, Keane TM, Kerns RD, Monson C, Scioli E. The development of an integrated treatment for Veterans with comorbid chronic pain and posttraumatic stress disorder. 
Pain Med. 2009;10(7):1300-11. [PMID:19818040] http://dx.doi.org/10.1111/j.1526-4637.2009.00715.x

37. Bair MJ, Robinson RL, Katon W, Kroenke K. Depression and pain comorbidity: A literature review. Arch Intern Med. 2003;163(20):2433-45. [PMID:14609780] http://dx.doi.org/10.1001/archinte.163.20.2433

38. Banks SM, Kerns RD. Explaining high rates of depression in chronic pain: A diathesis-stress framework. Psychol Bull. 1996;119(1):95-110. http://dx.doi.org/10.1037/0033-2909.119.1.95

39. Birgenheir DG, Ilgen MA, Bohnert AS, Abraham KM, Bowersox NW, Austin K, Kilbourne AM. Pain conditions among Veterans with schizophrenia or bipolar disorder. Gen Hosp Psychiatry. 2013;35(5):480-84. [PMID:23639185]

http://dx.doi.org/10.1016/j.genhosppsych.2013.03.019

40. Engels G, Francke AL, van Meijel B, Douma JG, de Kam H, Wesselink W, Houtjes W, Scherder EJ. Clinical pain in schizophrenia: A systematic review. J Pain. 2014;15(5): 457-67. [PMID:24365324] http://dx.doi.org/10.1016/j.jpain.2013.11.005

41. Graubard BI, Korn EL. Predictive margins with survey data. Biometrics. 1999;55(2):652-59. [PMID:11318229] http://dx.doi.org/10.1111/j.0006-341X.1999.00652.x
Submitted for publication October 22, 2014. Accepted in revised form May 8, 2015.

This article and any supplementary material should be cited as follows:

Higgins DM, Buta E, Dorflinger L, Masheb RM, Ruser CB, Goulet JL, Heapy AA. Prevalence and correlates of painful conditions and multimorbidity in national sample of overweight/obese Veterans. J Rehabil Res Dev. 2016; 53(1):71-82.

http://dx.doi.org/10.1682/JRRD.2014.10.0251

ORCID: Diana M. Higgins, PhD: 0000-0002-6885-266X; Alicia A. Heapy, PhD: 0000-0003-1284-8263; Joseph L. Goulet, MS, PhD: 0000-0002-0842-804X.

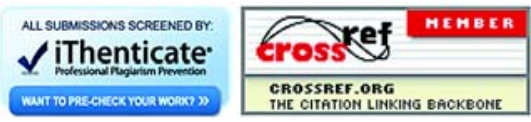

